\title{
EDITORIALS
}

\section{The NHS outcomes framework 2012-3}

\author{
The framework continues to develop but its implementation will pose many challenges
}

\author{
David A Cromwell senior lecturer, Nicholas Mays professor of health policy \\ Department of Health Services Research and Policy, London School of Tropical Medicine and Hygiene, London WC1E 7HT, UK
}

The NHS outcomes framework forms a central part of the English NHS reforms. It is planned to be part of the system of accountability between the secretary of state for health and the new NHS Commissioning Board, and it is designed to ensure that local clinical commissioning groups focus on the outcomes achieved for patients rather than the process used to achieve them. ${ }^{1}$ Clinical commissioning groups will be able to contract with any qualified healthcare provider, a freedom that is expected to deliver innovation and increase productivity, ${ }^{2}$ but the care delivered to patients should also be consistent with a high quality evidence based service described in the quality standards. $^{3}$

The Commissioning Board will be expected to achieve improvements on the indicators in the framework. ${ }^{1}$ The required level of improvement will reflect the cost effectiveness of potential actions and inequalities in outcomes between disadvantaged groups and areas. To reduce the risk of the Commissioning Board focusing on a narrow set of priorities, the framework covers a broad array of NHS activity. This has stimulated a substantial amount of work aimed at producing a robust set of outcome indicators, and refinements to the framework are expected to be ongoing.

In the 2012-3 framework, the number of indicators has increased from 51 to 60 , some indicator definitions have been altered, and the method of calculating 36 indicators has been finalised. Four indicators are still to be developed and 20 others are to be finalised.

Many changes are welcome, such as new indicators that extend the framework to cover services for patients with dementia and for people with learning difficulties. Other changes have made indicators more specific. For example, the 2011-2 indicator on patient reported outcomes after elective surgery combined information about four procedures (surgery for groin hernias, hip replacement, knee replacement, and varicose vein surgery), but it would have been difficult to interpret this composite indicator because the treatment effect for each procedure is different. ${ }^{4}$ This indicator has now been replaced by separate indicators for the four procedures.

The new commitment to align the NHS outcomes framework with the public health outcomes framework and the adult social care outcomes framework is another welcome development.
The importance of clinical and public health services to population health was recently illustrated by a study that estimated that half the decline in deaths from coronary heart disease in the United States between 1980 and 2000 was due to the reduced prevalence of major risk factors and half to improved treatment. ${ }^{5}$ Indicators on avoidable mortality will be shared with the public health outcomes framework, whereas indicators that will be shared with the adult social care outcomes framework will cover older people who require rehabilitation, people with long term conditions, people with mental illness, and carers. This is aimed at promoting greater cooperation between services. However, it is unclear whether the incentives for cooperation will outweigh other pressures, such as budget constraints. This is particularly uncertain for NHS and public health services because of the planned fragmentation of public health responsibilities between the Department of Health and local government. ${ }^{6}$

The construction of specific indicators also raises questions. Several indicators use the EuroQol (EQ-5D) scale-a generic measure of health status - as the outcome metric, even though better alternatives are available. For elective hip replacement, the Oxford hip score has been recommended ahead of the EQ-5D for the assessment of outcomes, ${ }^{7}$ and data from this disease specific measure are collected nationally.

For other indicators, such as that on neonatal death, it is not clear whether variations in outcomes will predominantly reflect the quality of care and whether cost effective actions that produce better outcomes are available to the NHS. No one would dispute that it is profoundly important to measure and reduce the rate of neonatal death. However, for a substantial proportion of deaths, there is no obvious maternal risk factor, and research into better prevention remains a priority. ${ }^{8}$

The example of the neonatal mortality indicator also highlights the challenge that the Commissioning Board will face in translating the framework into a system for holding clinical commissioning groups to account. Although a fourfold difference was seen between primary care trusts in the 2008 rates of neonatal mortality, the Centre for Maternal and Child Enquiries (CMACE) concluded that much of this was the result of random variation. ${ }^{9}$ To inspire public confidence, any system of accountability needs to be built around indicators that can 
detect systematic differences between organisations. It would be useful if the technical documentation on the framework included information for each indicator on how much of the variation observed between organisations arises from unexplained differences as opposed to random variation.

The NHS outcomes framework represents an evolution in the production of performance information on NHS services. It extends the definition of quality contained in High Quality Care for $A l l,{ }^{10}$ and many of its priority areas (as well as some indicators) are recognisable from the 2005-8 public service agreements. ${ }^{11}$ In 2012, work will continue on the technical challenges of defining indicators, and a public consultation is planned on the levels of improvement the board should aim to achieve. ${ }^{1}$ An improvement to the quality and range of information about healthcare outcomes is a positive development. It will increase transparency and, in general, aid accountability. However, accountability is also determined by the culture and behaviour of organisations and the power relationships between them. ${ }^{12}$ Exactly how relationships and organisational cultures will develop in the new commissioning regime remains to be seen, and it not yet clear that the new NHS outcomes framework will prove to be fit for purpose.

Competing interests: All authors have completed the ICMJE uniform disclosure form at www.icmje.org/coi_disclosure.pdf (available on request from the corresponding author) and declare: no support from any organisation for the submitted work; no financial relationships with any organisations that might have an interest in the submitted work in the previous three years; no other relationships or activities that could appear to have influenced the submitted work.

Provenance and peer review: Commissioned; not externally peer reviewed.

1 Department of Health. The NHS outcomes framework 2012-13. 2011. www.dh.gov.uk/ en/Publicationsandstatistics/Publications/PublicationsPolicyAndGuidance/DH 131700.

2 Department of Health. Equity and excellence: liberating the NHS. 2010. www.dh.gov.uk/ en/Publicationsandstatistics/Publications/PublicationsPolicyAndGuidance/DH_117353.

3 National Institute for Health and Clinical Excellence. NICE quality standards. 2012. http: //guidance.nice.org.uk/qualitystandards/qualitystandards.jsp.

4 NHS Information Centre for health and social care. Finalised patient reported outcome measures (PROMs) in England April 2009-March 2010: pre- and post-operative data. Experimental statistics. www.hesonline.nhs.uk.

5 Ford ES, Ajani UA, Croft JB, Critchley JA, Labarthe DR, Kottke TE, et al. Explaining the decrease in US deaths from coronary disease, 1980-2000. N Engl J Med 2007;356:2388-98.

6 McKee M, Hurst L, Aldridge RW, Raine R, Mindell JS, Wolfe I, et al. Public health in England: an option for the way forward? Lancet 2011;378:536-9.

7 Ostendorf M, van Stel HF, Buskens E, Schrijvers AJ, Marting LN, Verbout AJ, et al. Patient-reported outcome in total hip replacement. A comparison of five instruments of health status. J Bone Joint Surg Br 2004;86:801-8.

8 Flenady V, Middleton P, Smith GC, Duke W, Erwich JJ, Khong TY, et al. Stillbirths: the way forward in high-income countries. Lancet 2011;377:1703-17.

9 Centre for Maternal and Child Enquiries. Perinatal mortality 2008: United Kingdom. 2010. www.hqip.org.uk/assets/NCAPOP-Library/CMACE-Reports/36.-July-2010-PerinatalMortality-2008.pdf.

10 Department of Health. High quality care for all: NHS next stage review final report. 2008. www.dh.gov.uk/en/Publicationsandstatistics/Publications/PublicationsPolicyAndGuidance/ DH_085825.

11 Department of Health. Technical note for the spending review 2004. Public Service Agreement 2005-8. 2006. www.dh.gov.uk/en/Publicationsandstatistics/Publications/ PublicationsPolicyAndGuidance/DH 065226 .

12 Maybin J, Addicott R, Dixon A, Storey J. Accountability in the NHS. Implications of the government's reform programme. King's Fund, 2011. www.kingsfund.org.uk/document. $\mathrm{rm}$ ?id=9144.

Cite this as: BMJ 2012;344:e1080

(c) BMJ Publishing Group Ltd 2012 